Article

\title{
Optimization and Modeling of Material Removal Rate in Wire-EDM of Silicon Particle Reinforced Al6061 Composite
}

\author{
Deepak Doreswamy ${ }^{1, *(\mathbb{D})}$, Anupkumar M. Bongale ${ }^{2, *(\mathbb{D}}$, Marcin Piekarski ${ }^{3}$, Arunkumar Bongale ${ }^{4}(\mathbb{D}$, \\ Satish Kumar ${ }^{4,5}{ }^{\mathbb{D}}$, Danil Yurievich Pimenov ${ }^{6}$, , Khaled Giasin ${ }^{7}$ and Krzysztof Nadolny ${ }^{8}$ (i)
}

1 Department of Mechatronics Engineering, Manipal Institute of Technology, Manipal Academy of Higher Education, Manipal 576104, India

2 Department of Computer Science and Information Technology, Symbiosis Institute of Technology, Symbiosis International (Deemed University), Lavale, Pune 412115, Maharashtra, India

3 Mathematic and Physics Department, Gdansk University of Technology, G. Narutowicza 11/12, 80-233 Gdansk, Poland; piekarz2121@gmail.com

4 Department of Mechanical Engineering, Symbiosis Institute of Technology, Symbiosis International (Deemed University), Lavale, Pune 412115, Maharashtra, India; arunbongale1980@gmail.com (A.B.); satishkumar.vc@gmail.com (S.K.)

5 Symbiosis Centre for Applied Artificial Intelligence, Symbiosis International (Deemed university), Lavale, Pune 412115, Maharashtra, India

6 Department of Automated Mechanical Engineering, South Ural State University, Lenin Prosp. 76, 454080 Chelyabinsk, Russia; danil_u@rambler.ru

7 School of Mechanical and Design Engineering, University of Portsmouth, Portsmouth PO1 3DJ, UK; khaled.giasin@port.ac.uk

check for updates

Citation: Doreswamy, D.; Bongale, A.M.; Piekarski, M.; Bongale, A.; Kumar, S.; Pimenov, D.Y.; Giasin, K.; Nadolny, K. Optimization and Modeling of Material Removal Rate in Wire-EDM of Silicon Particle Reinforced Al6061 Composite. Materials 2021, 14, 6420. https:// doi.org/10.3390/ma14216420

Academic Editor: Irina Hussainova

Received: 2 October 2021

Accepted: 23 October 2021

Published: 26 October 2021

Publisher's Note: MDPI stays neutral with regard to jurisdictional claims in published maps and institutional affiliations.

Copyright: (c) 2021 by the authors. Licensee MDPI, Basel, Switzerland. This article is an open access article distributed under the terms and conditions of the Creative Commons Attribution (CC BY) license (https:/ / creativecommons.org/licenses/by/ $4.0 /)$.
8 Department of Production Engineering, Faculty of Mechanical Engineering, Koszalin University of Technology, Racławicka 15-17, 75-620 Koszalin, Poland; krzysztof.nadolny@tu.koszalin.pl

* Correspondence: deepak.d@manipal.edu (D.D.); ambongale@gmail.com (A.M.B.); Tel.: +91-720-430-8289 (D.D.); +91-984-463-3124 (A.M.B.)

Abstract: The mechanical, physical and interfacial properties of aluminum alloys are improved by reinforcing the silicon carbide particles $\left(\mathrm{SiC}_{\mathrm{p}}\right)$. Machinability of such alloys by traditional methods is challenging due to higher tool wear and surface roughness. The objective of research is to investigate the machinability of $\mathrm{SiC}_{\mathrm{p}}$ reinforced Al6061 composite by Wire-Electrical Discharge Machining (wire-EDM). The effect of wire-EDM parameters namely current $(\mathrm{I})$, pulse-on time $\left(\mathrm{T}_{\mathrm{on}}\right)$, wire-speed $\left(\mathrm{W}_{\mathrm{s}}\right)$, voltage $\left(\mathrm{I}_{\mathrm{V}}\right)$ and pulse-off time $\left(\mathrm{T}_{\text {off }}\right)$ on material removal rate (MRR) is investigated and their settings are optimized for achieving the high MRR. The experiments are designed by using Taguchi $\mathrm{L}_{16}$ orthogonal arrays. The MRR obtained at different experiments are analyzed using statistical tools. It is observed that all the chosen process parameters showed significant influence of on the MRR with contribution of $27.39 \%, 22.08 \%, 21.32 \%, 15.76 \%$ and $12.94 \%$ by $\mathrm{I}_{\mathrm{V}}, \mathrm{T}_{\text {off }}, \mathrm{T}_{\text {on }}$ and $\mathrm{W}_{\mathrm{s}}$, respectively. At optimum settings, the Wire-EDM resulted in MRR of $65.21 \mathrm{mg} / \mathrm{min}$ and $62.41 \mathrm{mg} / \mathrm{min}$ for samples with $4 \%$ and $8 \% \mathrm{SiC}_{\mathrm{p}}$. The results also indicated reinforcing $\mathrm{SiC}_{\mathrm{p}}$ upto $8 \%$ showed marginally low influence on MRR. Microstructural investigation of the cut surface revealed the presence of craters with wave pattern on its surface. The top surface of the crater is featured by the recast layers connecting adjacent craters. Further, the statistical model is developed using linear regression to predict the MRR $\left(R^{2}-73.65 \%\right)$ and its predicting accuracy is verified by the confirmation trials. The statistical model is useful for predicting the MRR for different settings of the process parameters. The optimized settings can be used to improve the machining productivity by increasing the MRR while machining of Al6061-SiC $\mathrm{p}_{\mathrm{p}}$ (upto 8 wt. \%) alloy by wire-EDM industries.

Keywords: Wire-Electrical Discharge Machining (Wire-EDM); material removal rate; wire speed; aluminium composite; silicon carbide particles; taguchi method 


\section{Introduction}

Wire-WEDM is a non-conventional machining method in which the removal of material occurs by the repetitive sparks produced between the electrode and the work material in the dielectric medium. The circulation of dielectric fluid carries away the molten debris from the machining zone. Wire-EDM is extensively used in the industries for producing the complex contours in the electrically conductive materials such as aluminium, copper, brass, titanium and other alloys. The advantages of wire-EDM over other processes are it can produce thin walls with very small radii of internal corners, minimal burrs, high dimensional accuracy, absence of mechanical stress, low surface roughness, fast processing and cost-effectiveness. Due to low density, the aluminium alloys are popularly used in transport applications (automobiles, aeroplanes and ships) for reducing the fuel consumption and thus carbon emission. The sector-wise usage is as follows: the transportation industry $-23 \%$, building and construction $-25 \%$, packaging industries $-8 \%$, engineering industries-11\% and electrical appliances-12\% [1]. In general, this metal possesses low density, good malleability, corrosion resistance and electricity conductivity. Aluminium 6000 series material shows excellent mechanical properties and weldability, thus it finds applications in aircraft fittings, electrical fittings and connectors, camera lens mounts, marines fittings and hardware, couplings, hinge pins, pistons, bike frames, valve parts, etc. [2,3].

The properties of aluminium can be further improved by alloying with other materials such as $\mathrm{SiC}, \mathrm{Al}_{2} \mathrm{O}_{3}, \mathrm{MgO}, \mathrm{WC}, \mathrm{S}_{\mathrm{i}} \mathrm{O}_{2}, \mathrm{~B}_{4} \mathrm{C}$, etc. Studies shows that yield strength, ultimate tensile strength, elastic modulus and hardness were improved by the addition of $\mathrm{SiC}$ and $\mathrm{Al}_{2} \mathrm{O}_{3}$ particles in aluminium matrix [4]. The addition, $\mathrm{Al}_{2} \mathrm{O}_{3}$, zirconium, cerium and magnesium resulted in decreasing the electrical conductivity of the composite [5]. The age hardened $\mathrm{Al} 6061-\mathrm{SiC}_{\mathrm{p}}$ reinforced composites showed the improvement in hardness by approximately $120-145 \%$ compared to as-cast alloy at aging temperature range of 100 to $200{ }^{\circ} \mathrm{C}$. The lower temperature aging showed substantial improvement in wear resistance compared to high temperature aging [6]. The addition of grain refiners (Al-5Ti-1B) led to size reduction and also transformed a longer and coarser grain to circular shaped and finer grains which significantly increased the hardness, tensile and wear resistance properties, but decreased the ductility [7]. $\mathrm{SiC}_{\mathrm{p}}$ are used as reinforcement particles because of its high ratio of strength to weight, thermal stability and wear resistance $[8,9]$. Investigation of micro-structural and mechanical properties of $\mathrm{Al} 6061$ with $\mathrm{SiC}_{\mathrm{p}}(500 \mathrm{~nm})$ showed the improvements in Young's modulus, strength and toughness [10]. Cao et al. [11] studied the effects of silicon and tungsten carbide reinforcement in aluminum matrix composites. The strong interfacial bond created between the matrix and the reinforced particles in these composites were found to transfer the load from the matrix and distributed to the reinforcement. This resulted in enhancement of the elastic modulus and the strength of composite. Nair et al. [12] made a review of metallurgy of Al-SiC composites in which the elastic stiffening effects of the $\mathrm{SiC}$ whiskers are detailed through continuum mechanics models. The type of reinforcement, its size, shape and quantity were found to significantly influence the mechanical properties [13].

Although aluminium possesses good machinability, the machining of $\mathrm{SiC}_{\mathrm{p}}$-reinforced aluminium alloys is challenging due to its abrasive nature which lead to rapid tool wear and affecting the surface quality $[14,15]$. The pull-out of the particle from the matrix and fracture of reinforced particles lead to formation of voids and cavities on the machined surface affecting the surface quality. In this scenario, the wire-EDM is one of the viable non-traditional methods in which the material removal occurs by rapid and repetitive sparks which occur by the electric discharge between the tool and workpiece. This causes the localized heating in the spark gap and the temperature developed is high enough to melt and vaporize the base metal. The dielectric fluid is circulated in the spark gap to control the electrical discharge and carry away the heat generated in machining [16]. The limitation of this process is requirement of electrically conductive work piece. The advantage of wire-EDM includes, machining is independent of mechanical properties 
of the work material, producing the complex profiles and the non-contact between tool and work piece during the machining. The research trends of wire-EDM mainly focus on scientific investigations of applications and optimization of the process parameters. In recent years, EDM is popularly used for making nozzles for automobiles, miniature hole for turbine blade cooling, biomedical device such as stents, micro-channels for microfluidic devices and the production of various micro-electro-mechanical devices, etc. [17]. The Wire-EDM is also found to be an effective tool for polishing applications of 3D printed parts in which about $80 \%$ of surface roughness was reduced [18]. The Wire-EDM polished 3D printed SS316L material showed the elimination the balling pits, voids and porosity. The high $t_{\text {on }}$ led to roughness due to prolonged duration of discharge, thus the low $t_{\text {on }}$ was encouraged for polishing application by wire-EDM. The negligible amount of wire electrode material deposition was seen on the polished on surface.

A. Pramanik [19] investigated the effect of reinforced $\mathrm{SiC}_{\mathrm{p}}$ size $(0.7-13 \mu \mathrm{m})$ in aluminium composites which were prepared by hot extrusion and heated treated (T1). The test samples with the smaller sized $\mathrm{SiC}_{\mathrm{p}}$ and $0 \%$ particles did not exhibit significant difference on the surface quality after wire-EDM. The smaller sized $\mathrm{SiC}_{\mathrm{p}}$ showed larger kerf width and lower electrode wear compared to test samples reinforced with larger particles size. Furthermore, matrix material was coated on the wire-electrode during the machining. The machining performance was found to be improved by mixing the multiwalled carbon nanotubes (MWCNTs) in the dielectric fluid. MWCNTs $(1 \mathrm{~g} / \mathrm{L})$ mixed with dielectric fluid enhanced the MRR by $75.42 \%$ and reduced the SR by $19.15 \%$ in wire-EDM of Nitinol shape memory alloy. In addition, a substantial reduction recast layer thickness and other surface defects were also observed [20]. P Sivaprakasam et al. [21] determined the machinability of A413-9\% composite using zinc coated copper wire in wire-EDM. The operating parameters such as voltage, capacitance and feed rate showed significant interaction effect on the kerf-width and surface roughness. The MRR was increased with increase in supply current and duration of pulse-on while machining of $\mathrm{SiC} / \mathrm{Al}$ composite [22-25]. When composition of $\mathrm{SiC}_{\mathrm{p}}$ is increased upto $15 \%$ in the matrix phase, the MRR was found to decrease and the further increase in $\mathrm{SiC}$ content showed the reverse trend. Agrawal et al. [26] investigated the surface roughness and MRR of AA6025 composite ( $\mathrm{SiC}: 10 \mathrm{wt}$ \% and $\mathrm{Al}_{2} \mathrm{O}_{3}: 10 \mathrm{wt}$. \%). The studies showed that the machining performance was improved by using conductive powder in the dielectric fluid. This is due to reduced strength of dielectric fluid by the conductive particles and increased the spark gap. This phenomenon assisted in ignition process by generating a stable and higher discharge in the spark gap [27]. Sidhu et al. [28] studied the EDM surface properties of $6 \% \mathrm{SiC} / \mathrm{A} 356.2,10 \% \mathrm{SiC}-5 \%$ quartz/ $\mathrm{Al}$ and 30\% $\mathrm{SiC} / \mathrm{A} 359$. The surface hardness was found to increase with increase in the density of the reinforced particles. In EDM, significant amount of metal transfer was found to occur from the copper electrode compared to graphite electrode. Dey et al. [29] optimized the wire-EDM parameters for machining of Al6061/ceno-sphere composite. The increase in pulse current and pulse-on time produced the larger craters and high surface waviness. This resulted in poor surface quality and increased electrode wear rate in $\mathrm{Al}(6351)-\mathrm{SiC}-\mathrm{B}_{4} \mathrm{C}$ Composite [30].

The weight and volume fraction of reinforcing particles affects the distribution of particles in the matrix which further affects the mechanical properties of the composite. The homogenous distribution of reinforced particles leads to uniform load distribution in the composite and hence improve its mechanical properties. However, higher loading of reinforced particles led to agglomeration which resulted in reduction of its mechanical properties due to improper load distribution [31,32]. The tensile strength and hardness were found to increase with the addition of $\mathrm{SiC}_{\mathrm{p}}$ up to $10 \mathrm{wt}$. \% beyond which these properties were gradually reduced. However, the ductility of the composite decreased with increase in $\mathrm{SiC}_{\mathrm{p}}$ content [33]. The stir casting of the test samples showed the agglomeration of the $\mathrm{SiC}_{\mathrm{p}}$ particles in the molten Al6061 matrix for the loading beyond $8 \mathrm{wt}$. \%. Considering this the weight fraction is restricted upto $8 \mathrm{wt}$ \% in this work. Machining of $\mathrm{Al}-\mathrm{SiC}_{\mathrm{p}}$ by traditional methods possess challenges of high tool wear-rate, formation of pits, voids, micro-cracks 
and fractured reinforcements on the cut surface. These challenges can be addressed by non-conventional machining methods such as wire-EDM. Considering these factors, an attempt is made in this work to investigate the effects of wire-EDM process parameters such as current, pulse-on and pulse-off time, wire speed and voltage on MRR and optimize these settings to improve the productivity in terms of MRR. Although, artificial neural networkbased optimization methods such as fuzzy AHP-ARAS [34], genetic algorithm [35], particle swarm, moth-flame and Grass-Hooper optimization [36] methods are more attractive tools of optimization for the experiments with large data sets, for limited experimental trails as in this work, Taguchi and response surface [37] methods are more viable methods. Therefore, this works adopts Taguchi method for optimization of MRR and to develop the regression model to predict the MRR. The model estimates the MRR for different settings of these process parameters.

\section{Materials and Methods}

This section provides the details of specimen preparation and experimental set up used for the investigation, settings of wire-EDM process parameters, design of experiments, measurement of the response parameter and optimization methodology.

\subsection{Experimental Set Up and Specimen Details}

Figure 1 shows the details of experimental facility used in the present work. The experiments are performed using a 2-axis (X-320 mm, Y-400 mm) computer numerically controlled wire-EDM made by Concord wire-EDM, Bangalore, India (Model: DK7732). Molybdenum wire (diameter: $0.16 \mathrm{~mm}$ ) is used tool electrode during the experiments. Mixture of soft water and gel is used as dielectric fluid. The resolution of the controller is $0.001 \mathrm{~mm}$. The SiC particle (size: $170 \mu \mathrm{m}$ ) reinforced Al-6061 alloy is prepared by stir-casting. The matrix material is liquefied at a temperature of $850{ }^{\circ} \mathrm{C}$ in a crucible and the pre-heated $\left(650{ }^{\circ} \mathrm{C}\right)$ reinforcing particles $(4 \%$ and $8 \%$ by weight) are added to molten metal and distributed uniformly in the matrix by mechanical stirrer. The liquefied metal is transferred to pre-heated (at $200{ }^{\circ} \mathrm{C}$ ) mold and then cooled to room temperature. General composition of Al6061 composite is shown in Table 1.

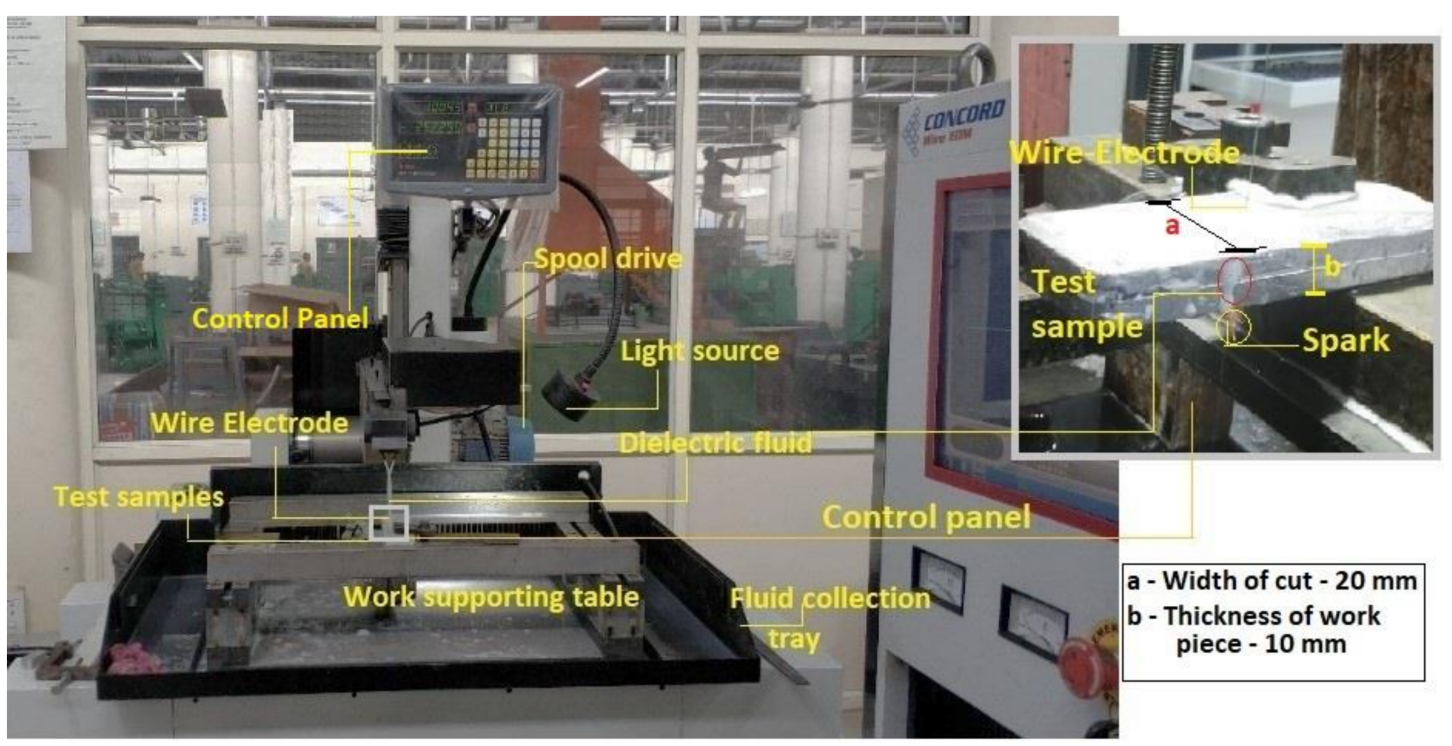

Figure 1. Experimental setup.

Table 1. Composition (\%) of Al6061.

\begin{tabular}{cccccccccc}
\hline $\mathbf{S i}$ & $\mathbf{F e}$ & $\mathbf{C u}$ & $\mathbf{M n}$ & $\mathbf{M g}$ & $\mathbf{C r}$ & $\mathbf{Z n}$ & $\mathbf{T i}$ & Others & Al \\
\hline $0.40-0.80$ & 0.70 & $0.15-0.40$ & 0.15 & $0.80-1.20$ & $0.04-0.35$ & 0.25 & 0.15 & 0.05 & Rest \\
\hline
\end{tabular}




\subsection{Design of Experiments}

The wire-EDM parameters such as current, pulse-on and pulse-off time, wire speed and voltage are chosen to study its effect on MRR. The voltage is varied at two different levels and remaining parameters are varied at four different levels. Table 2 details the wire-EDM process parameters and their chosen settings. These levels are selected based on the test experimentations. Total degree of freedom required for the experimental design is 13 , hence experiments are designed using $\mathrm{L}_{16}(45 \times 12)$ Taguchi orthogonal array. Table 3 shows the experimental design. The experiments were replicated for two trials in each experimental condition. Thickness of specimens $(10 \mathrm{~mm})$ and the supply pressure of dielectric fluid were kept constant during experiments.

Table 2. Wire-EDM process parameters and settings.

\begin{tabular}{ccccccc}
\hline Parameters & Unit & Code & $\mathbf{1}$ & $\mathbf{2}$ & $\mathbf{3}$ & $\mathbf{4}$ \\
\hline Current & A & A & 3 & 4 & 5 & 6 \\
Pulse-on time & H & B & 20 & 30 & 40 & 50 \\
Pulse-off time & $\mu \mathrm{S}$ & $\mathrm{C}$ & 10 & 15 & 20 & 25 \\
wire speed & RPM & D & 175 & 350 & 700 & 1400 \\
voltage & V & E & 80 & 90 & - & - \\
\hline
\end{tabular}

Table 3. The experimental design and corresponding average MRR.

\begin{tabular}{cccccccc}
\hline \multirow{2}{*}{ Trial No } & \multicolumn{3}{c}{ Settings of the Process Parameters } & \multicolumn{3}{c}{ MRR } \\
\cline { 2 - 7 } & $\mathbf{I}$ & $\mathbf{t}_{\mathbf{~} \mathbf{n}}$ & $\mathbf{t}_{\mathbf{~ o f f}}$ & $\mathbf{W}_{\mathbf{s}}$ & $\mathbf{V}$ & $\mathbf{4 \%}$ & $\mathbf{8 \%}$ \\
\hline 1 & 3 & 20 & 10 & 1400 & 80 & 0.317 & 0.307 \\
2 & 3 & 30 & 15 & 700 & 80 & 0.399 & 0.391 \\
3 & 3 & 40 & 20 & 350 & 90 & 0.369 & 0.361 \\
4 & 3 & 50 & 25 & 175 & 90 & 0.190 & 0.188 \\
5 & 4 & 20 & 15 & 350 & 90 & 0.487 & 0.477 \\
6 & 4 & 30 & 10 & 175 & 90 & 0.449 & 0.435 \\
7 & 4 & 40 & 25 & 1400 & 80 & 0.504 & 0.489 \\
8 & 4 & 50 & 20 & 700 & 80 & 0.398 & 0.391 \\
9 & 5 & 20 & 20 & 175 & 80 & 0.240 & 0.234 \\
10 & 5 & 30 & 25 & 350 & 80 & 0.313 & 0.310 \\
11 & 5 & 40 & 10 & 700 & 90 & 1.154 & 1.118 \\
12 & 5 & 50 & 15 & 1400 & 90 & 0.944 & 0.923 \\
13 & 6 & 20 & 25 & 700 & 90 & 0.616 & 0.610 \\
14 & 6 & 30 & 20 & 1400 & 90 & 0.532 & 0.519 \\
15 & 6 & 40 & 15 & 175 & 80 & 0.670 & 0.657 \\
16 & 6 & 50 & 10 & 350 & 80 & 0.736 & 0.716 \\
\hline
\end{tabular}

\subsection{Measurement of $M R R$}

Test specimens are subjected to wire-EDM for a length of $20 \mathrm{~mm}$ according to the design shown in Table 2. MRR obtained for each experimental trial is calculated by weight loss method during the machining as given by the Equation (1). The weight of the specimens before $\left(w_{i}\right)$ and after $\left(w_{f}\right)$ the machining is measured using digital mass balance (accuracy: $0.001 \mathrm{~g}$ ). For each test samples the measurements were made five times for the accuracy. Table 3 shows the average MRR of each trail for the samples with different composition of $\mathrm{SiC}_{\mathrm{p}}$. The cut surfaces of the test samples machined at different experimental conditions are shown in Figure 2.

$$
M R R=\frac{w_{i}-w_{f}}{t} m g / s
$$




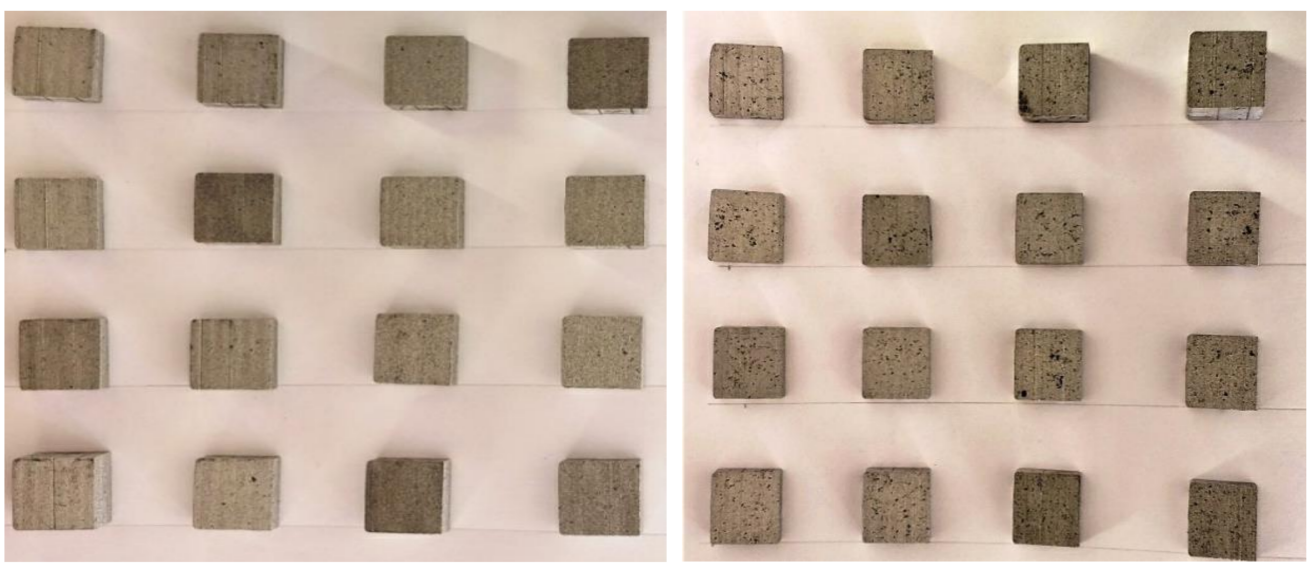

Figure 2. Cut surface of the machined samples.

\subsection{Optimization of Material Removal Rate}

The experimental results were analyzed by statistical method called Analysis of variance (ANOVA) to identify the effect of Wire-EDM parameters namely current, pulse-on and pulse-off time, wire speed and voltage on MRR. Significant process parameters are identified by conducting F-Test at confidence level of 95\%. Further, the average MRR obtained at different settings (Level) is determined. The optimum conditions which generate the high MRR is established based on the levels which produce highest MRR corresponding to each process parameters of the study. The MRR at optimized condition is computed using Equations (2)-(5) [38]. Finally, a statistical model is developed using regression analysis to establish to predict the MRR.

$$
\begin{gathered}
n_{\text {eff }}=\frac{n}{1+D F} \\
\mathrm{~T}=\frac{\sum M R R}{n} \\
M R R_{\text {Optimum }}= \\
\text { Confidence interval }= \pm \sqrt{F\left(\alpha, D F_{\text {error }}\right) \times \frac{M S_{\text {error }}}{n_{\text {eff }}}}
\end{gathered}
$$

\subsection{Theoretical Modelling of Material Removal}

In Wire-EDM, the material removal occurs through electric discharge in the spark gap. The spark energy developed during the sparking process is determined by Equation (6). The heat produced by the spark depends on current, pulse time and voltage. Although there are different models to predict the spark radius $\left(r_{s p}\right)$, the Gaussian heat input model is popularly used among the researchers $[38,39]$. According to this model, the maximum heat intensity $(q R)$ is at the axis of a spark and the corresponding heat flux is given by Equation (7) $[39,40]$. The electric field produced between electrode and work piece ionize the dielectric fluid which create the path for electrons movement. This lead to formation of spark whose temperature levels can melt and vaporize a tiny volume from the work piece. This phenomenon leads to creation of hemispherical shaped craters on the machined surface and its size can be estimated using Equation (8) [41].

$$
\begin{gathered}
E_{s}=I_{p} \times I_{V} \times t_{o n} \\
q_{f}(R)=\frac{4.45 \times W_{M} \times I \times V}{\Pi \times\left(r_{s p}\right)^{2}} \times e^{\left[-4.5\left(\frac{R}{r_{s p}}\right)^{2}\right]} \\
\Gamma=\frac{2}{3} \pi r^{3}
\end{gathered}
$$




\section{Results and Discussion}

\subsection{The Effect of Current and Wire Speed on MRR}

Figure 3a shows influence of current on MRR. It is observed that, the MRR is increased with increase in current from 3 to $5 \mathrm{~A}$. The maximum MRR of $0.662 \mathrm{mg} / \mathrm{s}$ is obtained at current of $5 \mathrm{~A}$. An increase in current level from low to high increase the breakdown voltage and raise its spark energy [36,37] as given by the Equation (6). Due to higher $\mathrm{E}_{\mathrm{s}}$, the high current results in melting and vaporization of more volume of material [41,42]. Similar trends were also reported by other researchers $[43,44]$. However, the current beyond $5 \mathrm{~A}$ showed a slight decrease in MRR. This may be due to insufficient flushing of molten pool which result in formation of recast layer on the preceding machined surface. Furthermore, increasing the discharge energy beyond the peak levels results in deposition of the debris which contain the decomposed product of dielectric fluid and the eroded particles from the wire-electrode. The current settings beyond the peak levels result in rapid deposition of the debris at the machining gap which leads to significant influence on the characteristics of dielectric breakdown and affects the material removal [45].
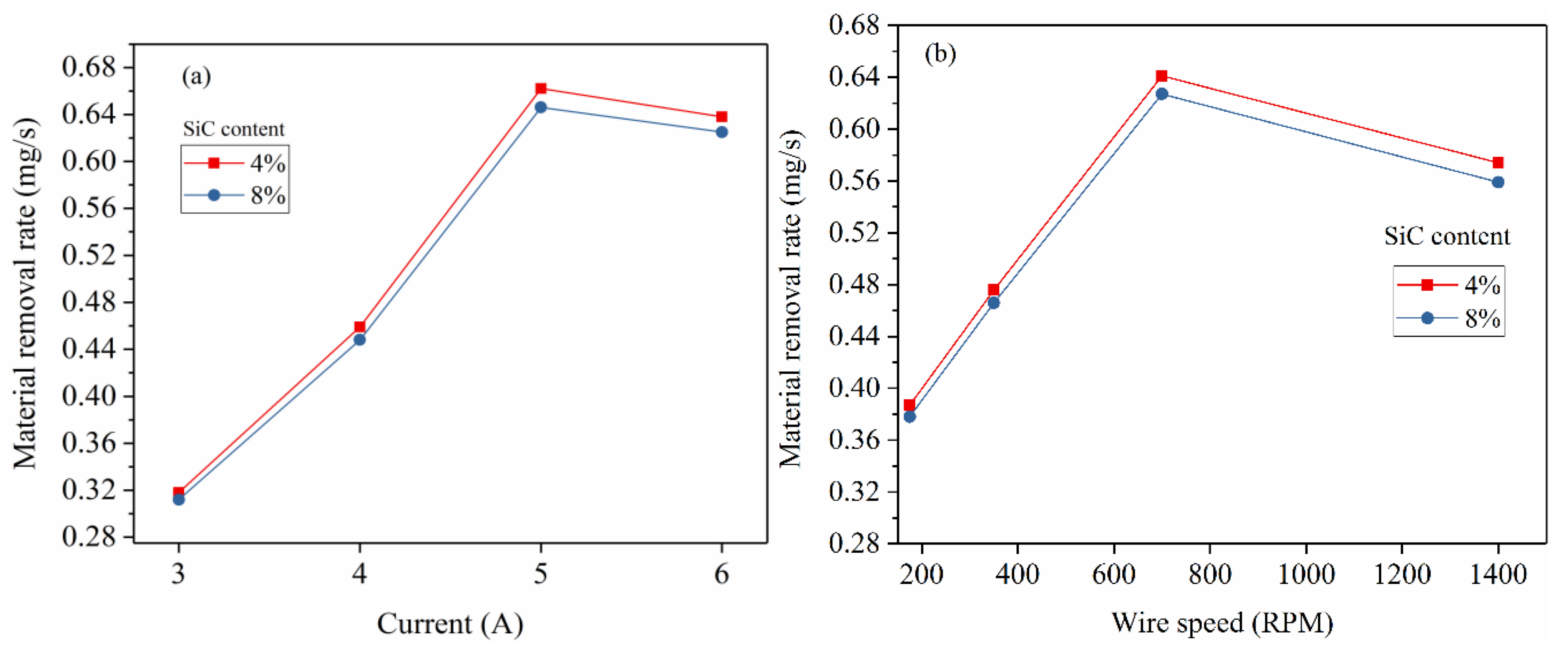

Figure 3. (a) The effect of current on MRR. (b) The effect of wire speed on MRR.

Further, Figure $3 b$ shows the influence of wire speed on MRR. The rotational speed of spool on which electrode wire is wrapped is varied from 175 to 1400 RPM and its corresponding MRR obtained is shown in Figure $3 b$. The MRR is increased from $0.387 \mathrm{mg} / \mathrm{s}$ to $0.641 \mathrm{mg} / \mathrm{s}$ due to change in spool rotational speed up to $700 \mathrm{RPM}$. Further increase of spool rotational speed appears to be counterproductive which reduced the MRR by $10.45 \%$. This is attributed to the fact that the amount of spark energy available for machining reduces with increase in wire speed [46]. As a result, the MRR drops for the wire-speed settings beyond the optimum speed.

\subsection{The Effect of Pulse-On Time and Pulse-Off Time on MRR}

The effect of pulse-on time, pulse-off time on MRR is shown in Figure 4a,b, respectively. It is observed that increase in pulse-on time from $20 \mu \mathrm{s}$ to 40 increased the MRR. The energy (E) of each spark is given by $\mathrm{E}=\mathrm{V} \times \mathrm{I} \times \mathrm{t}_{\mathrm{on}}$, where $\mathrm{V}$-voltage, $\mathrm{I}$-current and pulse-on time. This indicate that the longer spark duration (pulse-on time) releases more spark energy in each spark cycle, resulting in melting of material with larger crater size (i.e., MRR is directly proportional to crater radius). However, the pulse-on time beyond $40 \mu$ s showed reduction in MRR from $0.674 \mathrm{mg} / \mathrm{s}$ to $0.567 \mathrm{mg} / \mathrm{s}$. This may be due to recasting of the part of molten pool around the craters due to longer cycle time and the reduced spark frequency as seen in Figure 5. 

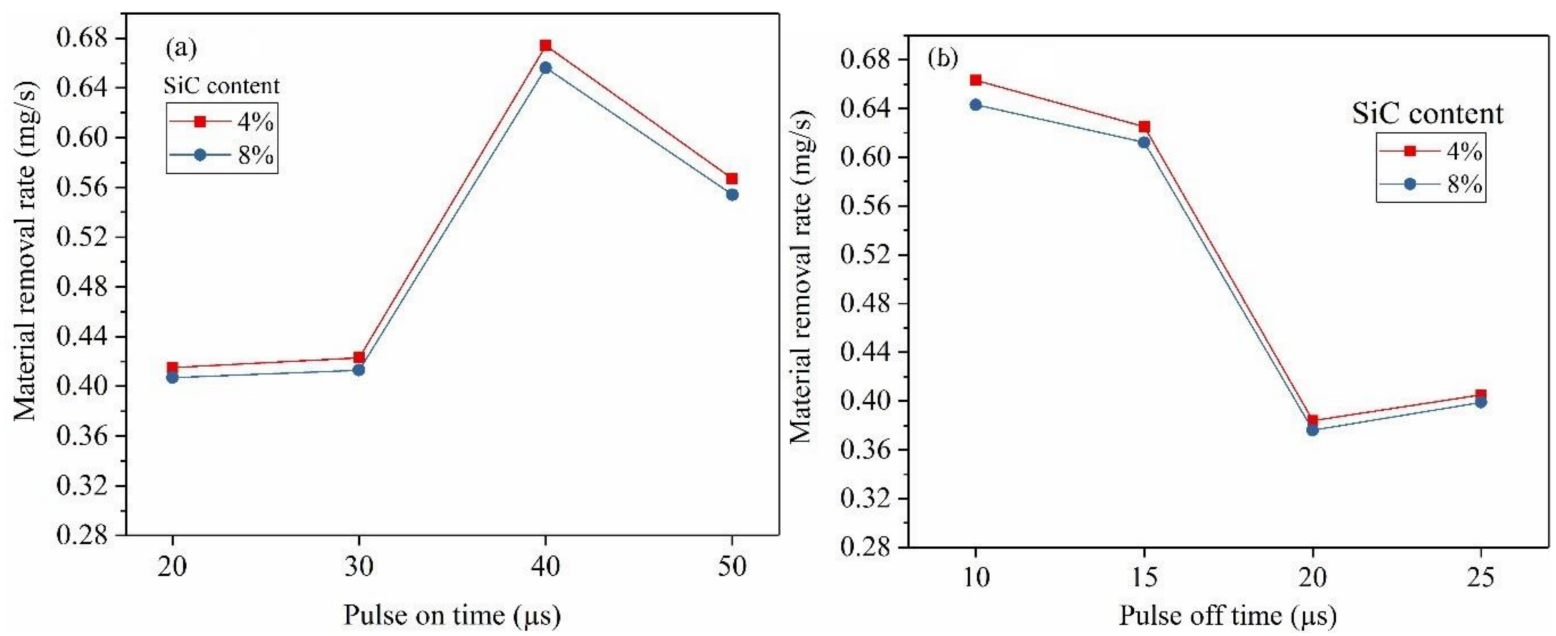

Figure 4. (a) The effect of Pulse-on time on MRR. (b) The effect of Pulse-off time on MRR.

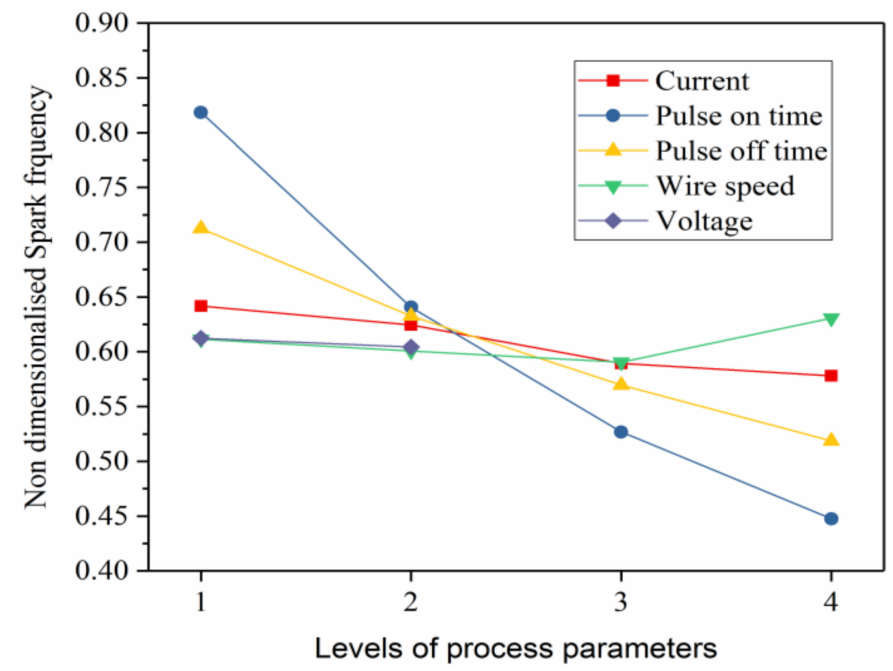

Figure 5. The spark frequency at different levels.

Interestingly, increase in the pulse-off time from $10 \mu$ s to $25 \mu$ s resulted in steady decrease in MRR as shown in Figure $4 \mathrm{~b}$. Pulse-off time is the time duration at which sparking do not occur. Therefore, increasing the pulse of time increase the cycle time and also reduce the spark frequency as shown in Figure 5. This resulted in decreasing the MRR with increase in pulse-off time.

\subsection{The Effect of Voltage on $M R R$}

The effect of voltage on MRR is shown in Figure 6. It is observed that MRR is directly proportional to voltage. The MRR is increased by $24.45 \%$ with increase voltage from $80 \mathrm{~V}$ to $90 \mathrm{~V}$ in the spark gap. As explained earlier, the spark energy is a function of voltage, current and pulse-on time (i.e., $\mathrm{E}=\mathrm{V} \times \mathrm{I} \times \mathrm{t}_{\mathrm{on}}$ ). Therefore, the increase in voltage resulted in melting and vaporization of greater volume of material and results in increasing the MRR. 


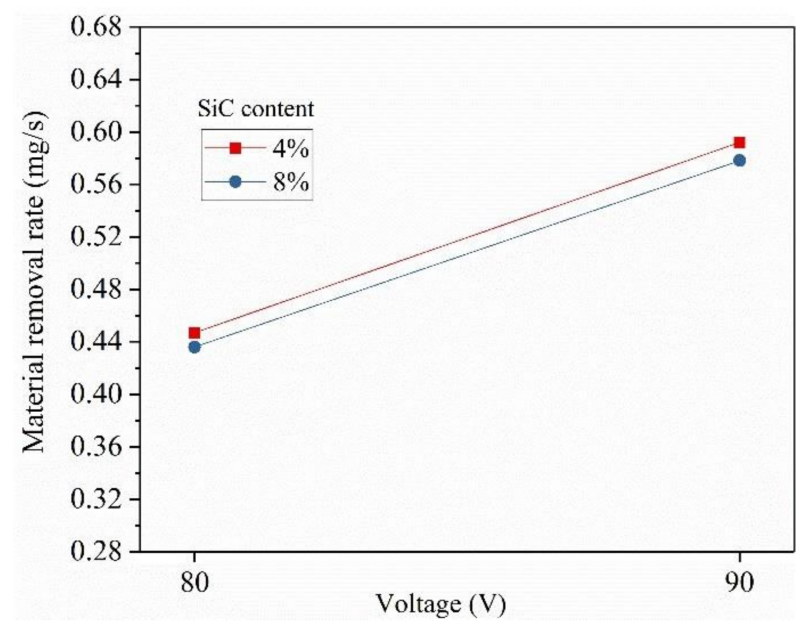

Figure 6. The effect voltage on MRR.

\subsection{Morphological Study of Machined Surfaces}

Morphological study of the machined surfaces is carried out using scanning electron microscopy (SEM). Figures 7-13 shows the details of microstructural details of cut surfaces. Figures 7 and 8 shows that the machined surface is characterized by the circular shaped craters surrounded by the peaks and valley formed by the re-solidified molten metal pool. The electric spark produced between the wire-electrode and the work piece generates sudden pressure on the dielectric fluid. The series of shockwaves thus formed exert greater pressure on the molten metal pool which lead to formation of craters on the machined surface. The surfaces are also featured by some of the partly molten metal globules which are firmly intact with the machined surfaces.

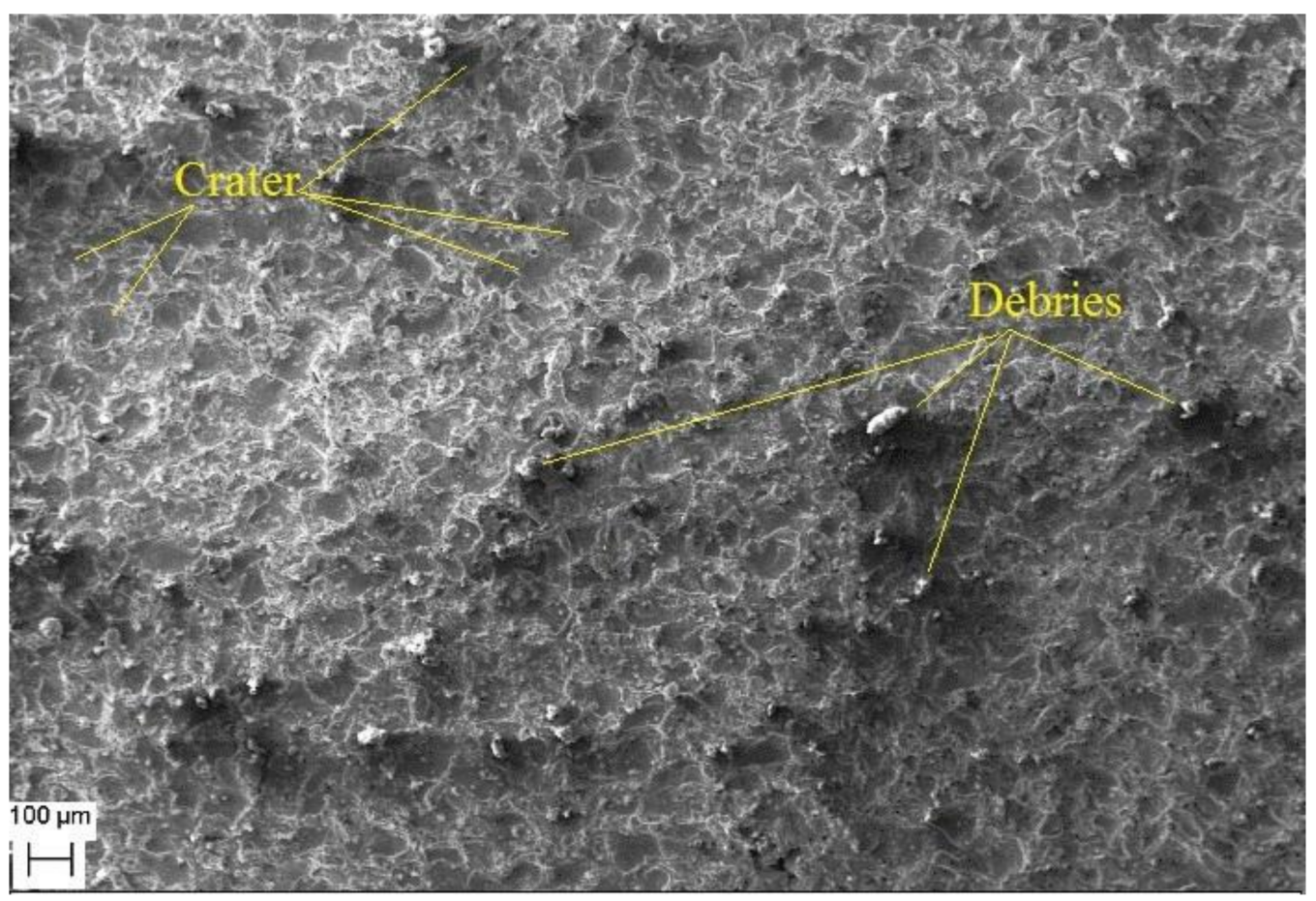

Figure 7. The cut surface. 


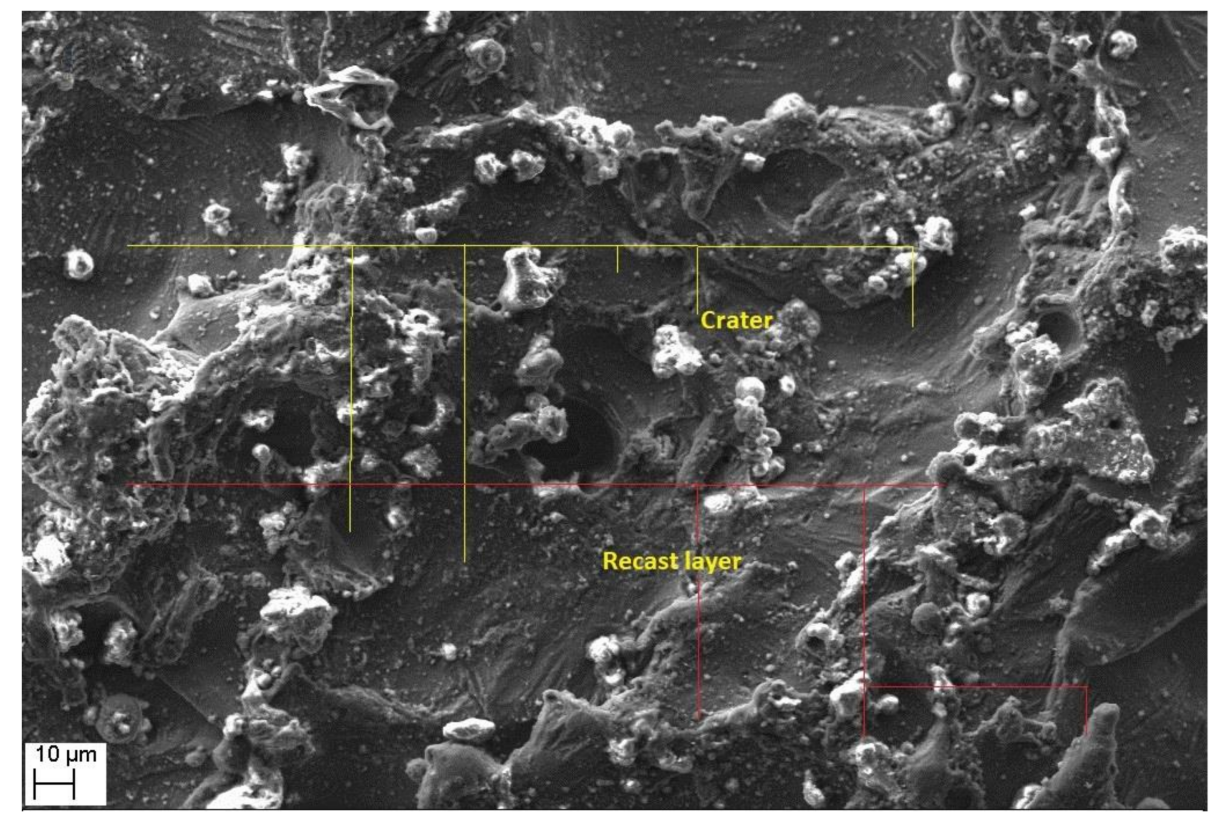

Figure 8. Magnified view of the recast layer and craters.

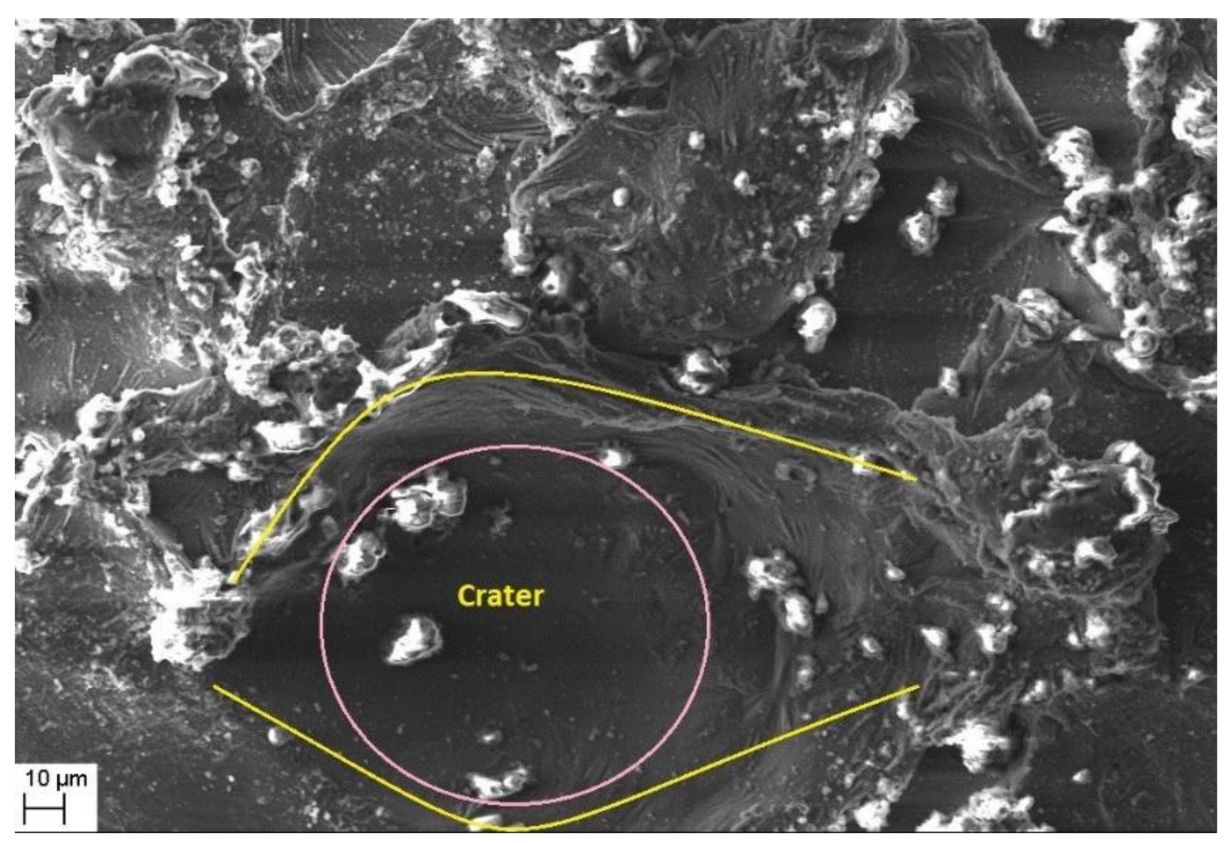

Figure 9. The crater formation. 


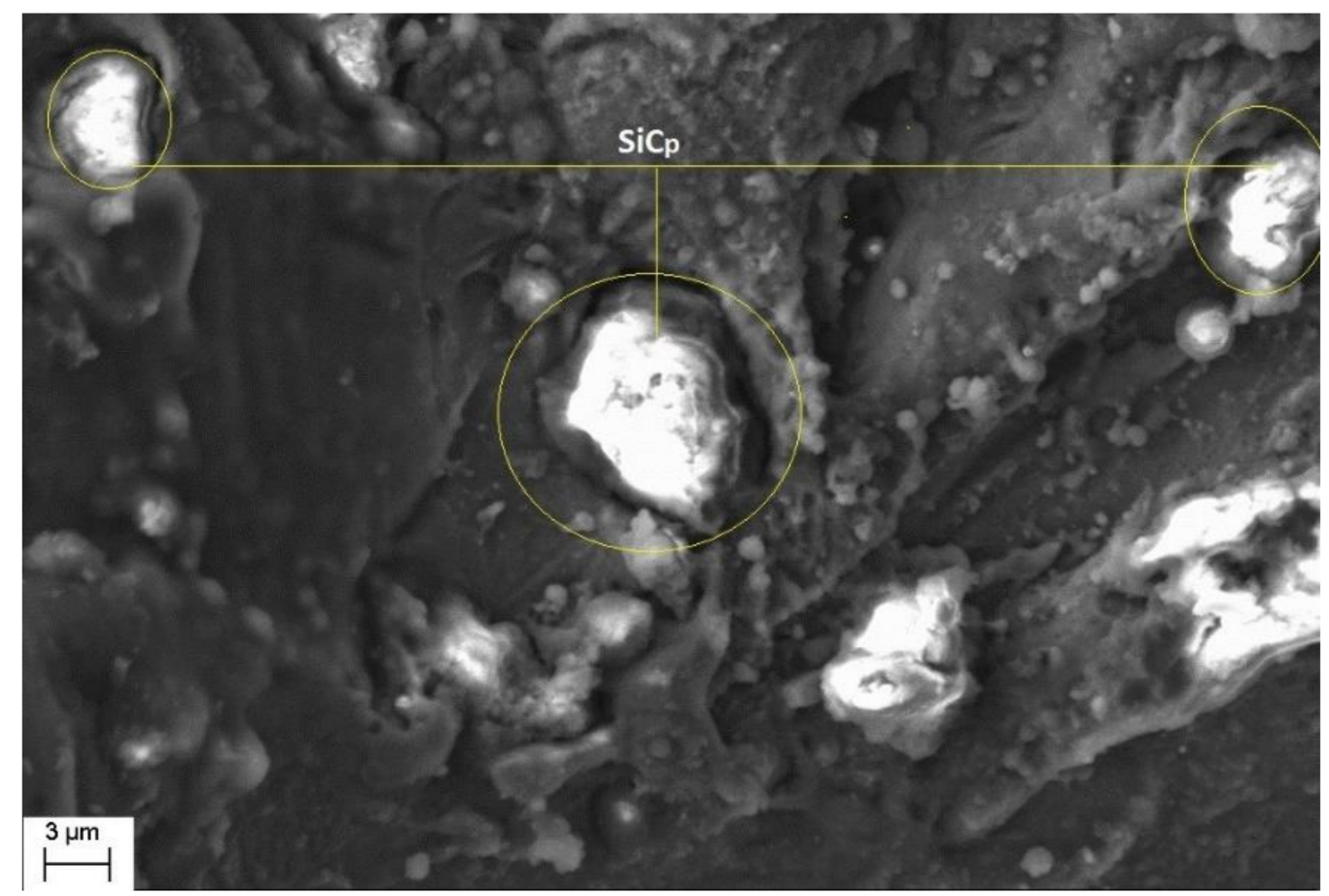

Figure 10. The intact $\mathrm{SiC}_{\mathrm{p}}$ on the cut surface.

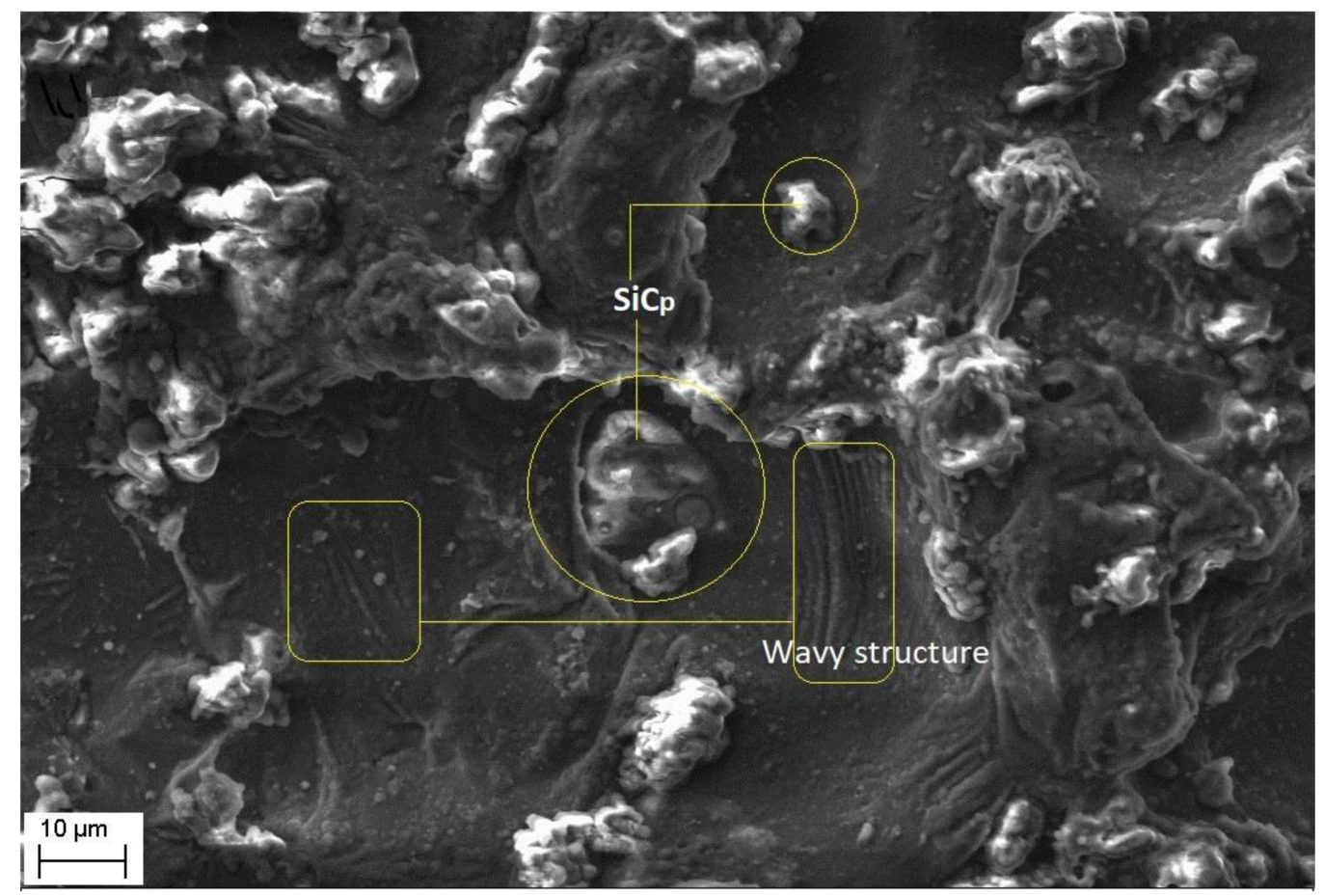

Figure 11. Formation of wavy patter on the crater surface. 


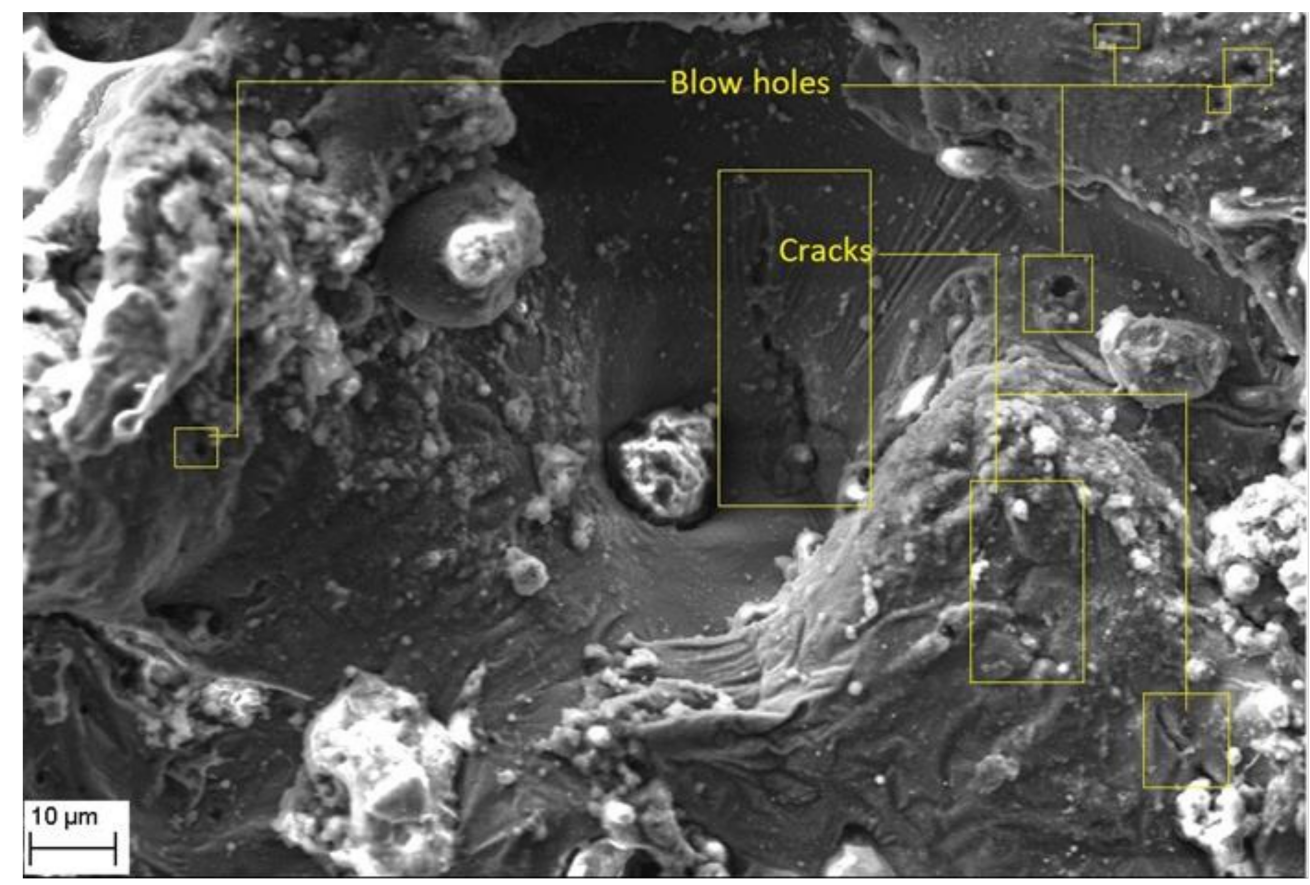

Figure 12. Cracks and blow hole formation on crater surface.

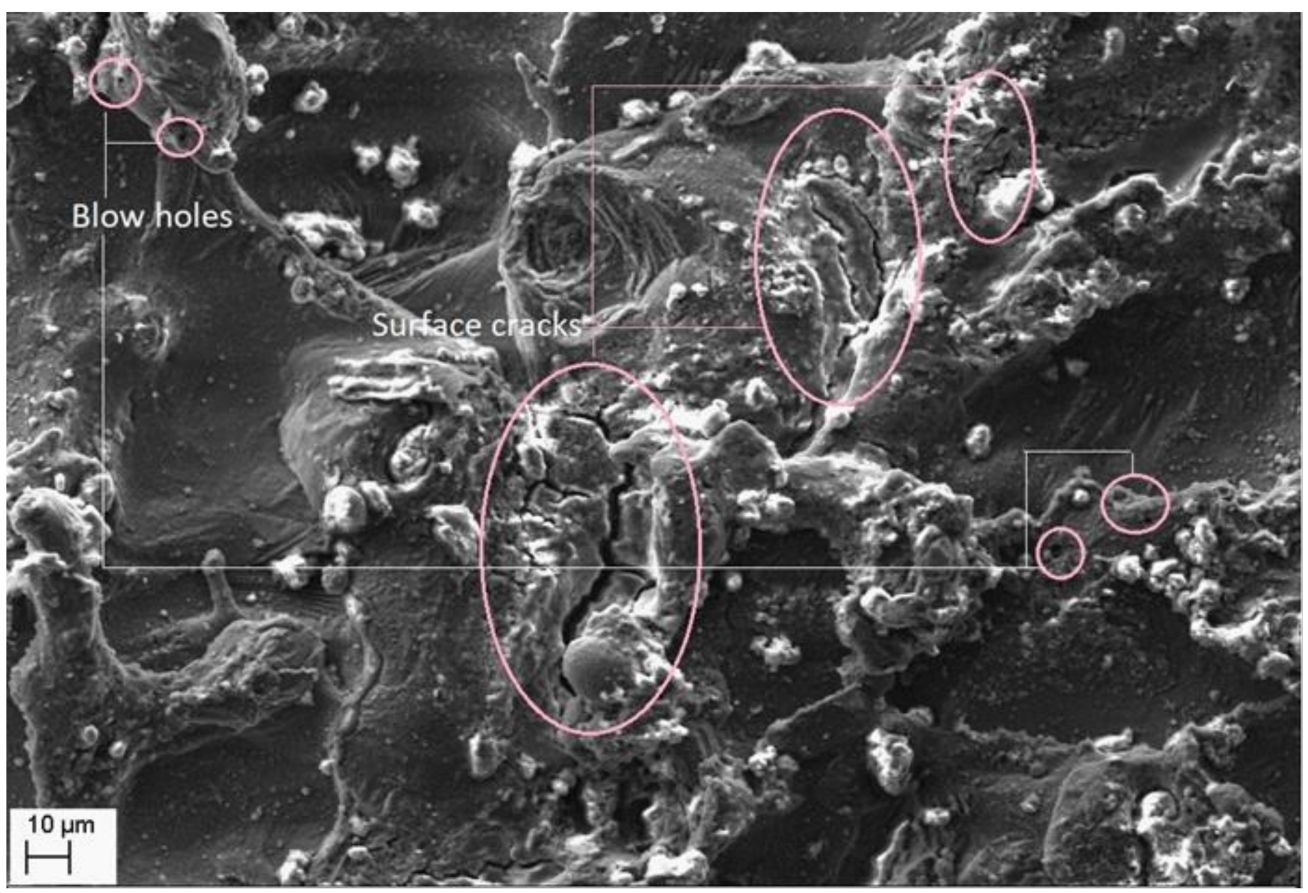

Figure 13. Cracks and voids on the recast layer.

Magnified views of these craters are shown in Figures 9-11. It is observed that the reinforced $\mathrm{SiC}_{\mathrm{p}}$ particles appear to intact the recast layer and a few particles are found to be relocated on the cut surface. This is due to circulation of the dielectric fluid in the machining process. As the dielectric fluid pass through the machining surface the heated reinforced particles which are in the molten pool are carried along with the flow and such debris gets welded on to the nearby locations on the machined surface during solidification of molten matrix pool. It is also observed from these figures that most of the crater appears confirms to the shape of truncated sphere. This is in confirmation with the Gaussian heat distribution model $[39,40]$ used to predict the spark radius. The boundary of the craters on 
the machined surface show elongated structure in the direction of wire travel. In fact, the crater surface shows a typical wavy pattern as shown in Figure 11. Further, the size of the reinforced $\mathrm{SiC}_{\mathrm{p}}$ is smaller than the spark gap and a part of the particle is partly bounded in the matrix material. The remaining protruded part is exposed to high temperatures in the spark gap. Figures 10-12 reveal that the protruded portion of the $\mathrm{SiC}_{\mathrm{p}}$ to get pushed further inside the molten matrix pool during the machining process. This is mainly due to the combined effect of impact of shock waves created by spark and mechanical moment by travelling wire electrode on the reinforced particles. These figures also show that all the $\mathrm{SiC}_{\mathrm{p}}$ are intact with the machined surface and debonding of the particles from the matrix is not seen.

Further, it is evident from Figures 12 and 13 that the machined surface shows the presence of micro-cracks and blow holes of very small size. These cracks are primarily formed due to the shrinkage of matrix material which occur by rapid and repetitive cooling of the molten pool by the circulating dielectric fluid. The presence of blow holes is mainly due to interdentritic segregation of alloying elements such as $\mathrm{Mg}$, Si, etc. present in Al6061 alloy and rapid cooling of molten metal. The gas evolved during the sparking process in the dielectric medium also contributes to the formation of the blow holes on the machined surface.

\subsection{Analysis of Variance (ANOVA) of MRR}

The results of ANOVA of the MRR are shown in Table 4. The F-test is conducted on the ANOVA data at $95 \%$ confidence level to identify process parameters which are significantly affecting MRR. The F-values of the current, gap voltage, pulse-on time and pulse-off time are found to be higher than the critical values and hence their effect on MRR is significant. Further, the percentage contribution of each process parameter is calculated. The current is the most significant parameter that contributed maximum (27.39\%) to variation of material removal rate followed by voltage $(22.08 \%)$, pulse-off time $(21.32 \%)$, pulse-on time $(15.76 \%)$ and wire speed (12.94\%).

Table 4. Analysis of variance for MRR.

\begin{tabular}{cccccccc}
\hline \multirow{2}{*}{ Source } & DF & \multicolumn{3}{c}{$\mathbf{4 \%}$ Sic } & \multicolumn{3}{c}{$\mathbf{8 \%}$ Sic } \\
\cline { 2 - 7 } & & Seq SS & Adj MS & F & Seq SS & Adj MS & F \\
\hline Current & 3 & 0.3004 & 0.1001 & 57.57 & 0.3148 & 0.1049 & 50.84 \\
Pulse-on time & 3 & 0.1729 & 0.0576 & 33.13 & 0.1854 & 0.0618 & 29.95 \\
Pulse-off time & 3 & 0.2338 & 0.0779 & 44.81 & 0.2524 & 0.0841 & 40.77 \\
Wire speed & 3 & 0.1419 & 0.0473 & 27.19 & 0.1492 & 0.0497 & 24.10 \\
Voltage & 1 & 0.0807 & 0.0807 & 46.41 & 0.0844 & 0.0844 & 40.92 \\
Residual Error & 2 & 0.0034 & 0.0017 & & 0.3148 & 0.1049 & \\
Total & 15 & 0.9334 & & & & & \\
\hline
\end{tabular}

DF: degree of freedom, MS: mean square, SS: sum of square.

\subsection{Optimum of Process Parameters}

The Taguchi method is adopted for the optimization of machining settings which produce maximum MRR while machining of Al6061-SiC $\mathrm{C}_{\mathrm{p}}$ composite by wire-EDM. Table 5 shows the average MRR obtained at different settings of process parameters. From the table, it is observed that the maximum MRR is achieved at the settings $A_{3} B_{3} C_{1} D_{2} E_{2}$, i.e., current: level $3(5 \mathrm{~A})$, pulse-on time: level $3(40 \mu \mathrm{s})$, pulse-off time: $10 \mu \mathrm{s}$ (level 1), drum/wire speed-level 3 (700 rpm) and voltage-90 V (level 2). The predicted MRR at this setting are $69.33 \mathrm{mg} / \mathrm{min}$ and $67.28 \mathrm{mg} / \mathrm{min}$ for samples with $4 \%$ and $8 \% \mathrm{SiC}_{\mathrm{p}}$, respectively. Further, the confirmation experiments are conducted, and the test results are shown in the Table 6 . It is seen that MRR obtained by the experiments is in agreement with the predicted MRR. Further, the maximum change (delta) in MRR due to change in settings of different process parameters at different levels is also shown in the same table. Based on the delta values, 
the process parameters are ranked in the order of their influence as current: I, pulse-off time: II, pulse-on time: III, wire-speed: IV and voltage: V.

Table 5. The average MRR.

\begin{tabular}{|c|c|c|c|c|c|}
\hline Level & Current & Pulse-On Time & Pulse-Off Time & Wire Speed & Voltage \\
\hline \multicolumn{6}{|c|}{$4 \% \mathrm{SiC}_{\mathrm{p}}$} \\
\hline 1 & 0.318 & 0.415 & 0.663 & 0.574 & 0.447 \\
\hline 2 & 0.459 & 0.423 & 0.625 & 0.641 & 0.592 \\
\hline 3 & 0.662 & 0.674 & 0.384 & 0.476 & - \\
\hline 4 & 0.638 & 0.567 & 0.405 & 0.387 & - \\
\hline Delta & 0.344 & 0.259 & 0.279 & 0.254 & 0.145 \\
\hline \multicolumn{6}{|c|}{$8 \% \mathrm{SiC}_{\mathrm{p}}$} \\
\hline 1 & 0.312 & 0.407 & 0.643 & 0.378 & 0.436 \\
\hline 2 & 0.448 & 0.413 & 0.612 & 0.466 & 0.578 \\
\hline 3 & 0.646 & 0.656 & 0.376 & 0.627 & - \\
\hline 4 & 0.625 & 0.554 & 0.399 & 0.559 & - \\
\hline Delta & 0.334 & 0.249 & 0.267 & 0.249 & 0.142 \\
\hline
\end{tabular}

Table 6. The predicted and experimental MRR $(\mathrm{mg} / \mathrm{min})$ at optimum conditions.

\begin{tabular}{ccccccc}
\hline \multirow{2}{*}{ Trial No } & \multicolumn{3}{c}{$\mathbf{4 \%}$} & \multicolumn{3}{c}{$\mathbf{8 \%}$} \\
\cline { 2 - 6 } & Predicted & Experimental & Error & Predicted & Experimental & Error \\
\hline 1 & 69.33 & 65.66 & $5.30 \%$ & 67.28 & 62.52 & $7.08 \%$ \\
2 & 69.33 & 64.57 & $6.87 \%$ & 67.28 & 61.96 & $7.90 \%$ \\
3 & 69.33 & 66.15 & $4.58 \%$ & 67.28 & 63.30 & $5.91 \%$ \\
4 & 69.33 & 64.46 & $7.00 \%$ & 67.28 & 61.88 & $8.02 \%$ \\
\hline
\end{tabular}

\subsection{Regression Modelling of MRR}

This section describes the details of developing the statistical model to predict the MRR for different settings of the process parameters which is possible in wire-EDM (Model: Concord/DK7732). A statistical model is developed to establish relationship of I: Current, $t_{o n}$ : Pulse-on time, $t_{\text {off: }}$ Pulse-off time, $w_{s}$ : wire-speed, $I_{v}$ : voltage and the MRR. The main effect of these parameters is considered in the modelling. The generalized form of the regression model is given by Equation (9), and the developed model is given by Equation (10) for the samples with $4 \%$ and $8 \% \mathrm{SiC}_{\mathrm{p}}$. The coefficient of determination $\left(R^{2}\right)$ for the equation is $73.6 \%$.

$$
y=c+k_{1} \times x_{1}+k_{2} \times x_{2}+\ldots \ldots \ldots+k_{n} \times x_{n}
$$

where,

$$
\begin{aligned}
& y \text {-dependent parameter; } \\
& c \text {-model constant; } \\
& x_{1} \cdots \cdots x_{n} \text {-control parameter; } \\
& k_{1} \cdots \cdots k_{n} \text {-coefficients of control parameters. } \\
& \text { MRR }=-1.20+0.114 \times I+0.00685 \times t_{o n}-0.0194 \times t_{o f f}+0.000135 \times w_{s}+0.0142 \times I v
\end{aligned}
$$

The accuracy of predicting MRR by regression model is tested by conducting confirmation experiments within the range of operating parameters, that is, $3 \leq \mathrm{I} \leq 6 ; 20 \leq \mathrm{t}_{\mathrm{on}} \leq 50$; $10 \leq \mathrm{t}_{\text {off }} \leq 25 ; 375 \leq \mathrm{w}_{\mathrm{s}} \leq 1400 ; 80 \leq \mathrm{I}_{\mathrm{v}} \leq 90$. The distribution of residuals of the model is shown in Figure 14a which shows that the residuals are distributed around the line of fit linearly and hence confirms the adequacy test model linearity. Figure 14b shows the MRR predicted by the regression model and the experimentally obtained. It is observed that the actual MRR for the test sample with $4 \mathrm{wt}$. $\%$ and $8 \mathrm{wt} . \%$ are close to each other. The 
minimum and average predication error MRR is $4.45 \%$ and $20.46 \%$, respectively. Standard deviation of error 2.19.

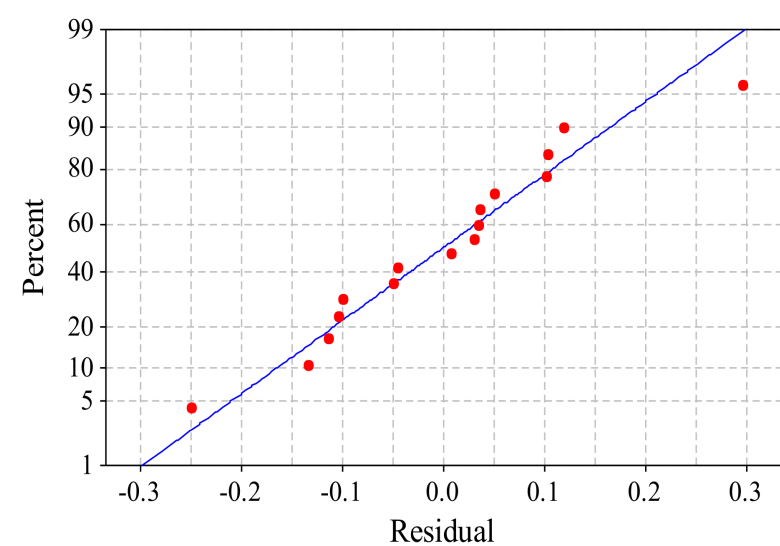

(a)

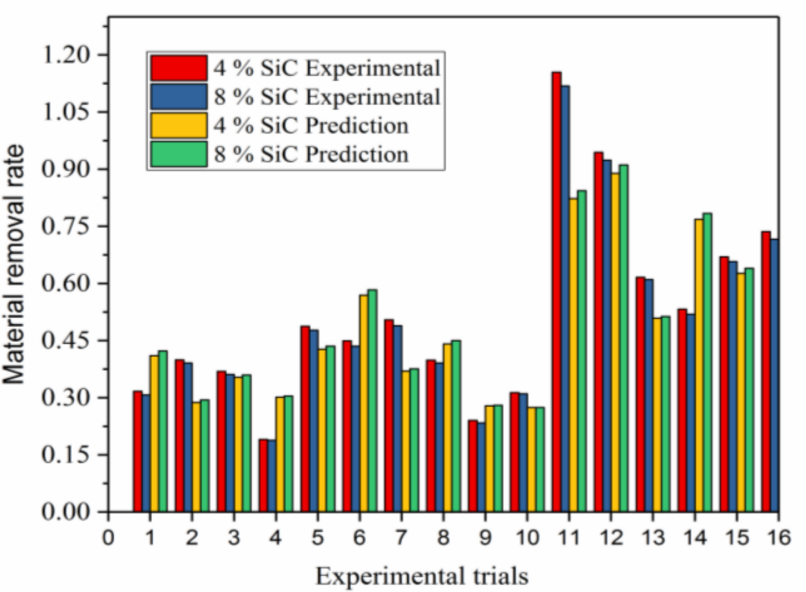

(b)

Figure 14. (a) Distribution of residuals. (b) Comparison of MRR predicted by model with experimental results.

\section{Conclusions}

This study investigated the effect of parameters such as $I, t_{o n}, t_{o f f}, w_{s}, I_{v}$ on machining of 4 wt. \% to 8 wt. \% $\mathrm{SiC}_{\mathrm{p}}-\mathrm{Al} 6061$ alloy by wire-EDM. These parameters are optimized to improve the MRR. The statistical model developed is useful for predicting the MRR for different settings of the process parameters. The optimized settings can be used to improve the productivity by increasing the MRR while machining of Al6061-SiC $\mathrm{p}_{\mathrm{p}}$ (up to $8 \mathrm{wt}$. \%) alloy by wire-EDM industries. The following conclusions are drawn based on the results obtained.

- The current, $t_{o n}, t_{o f f}$, wire speed and voltage showed significant influence on MRR. The MRR increased with increase in current, $t_{o n}$, wire speed and voltage, but it decreased with increasing the $t_{\text {off }}$ and also $w_{s}$ beyond $700 \mathrm{rpm}$.

- The current contributed to maximum (27.39\%) variation of MRR followed by voltage $(22.08 \%), t_{\text {on }}(21.32 \%), t_{\text {off }}(15.76 \%)$ and $w_{s}(12.94 \%)$.

- The optimum settings which produced highest MRR $(65.21 \mathrm{mg} / \mathrm{min}$ and $62.41 \mathrm{mg} / \mathrm{min}$ for samples with $4 \%$ and $8 \% \mathrm{SiC}_{\mathrm{p}}$ ) are current $-5 \mathrm{~A}, t_{\text {on }}-40 \mu \mathrm{s}, t_{\text {off }}-10 \mu \mathrm{s}, w_{\mathrm{s}}-700 \mathrm{rpm}$ and voltage- $-90 \mathrm{~V}$.

- $\quad$ Addition of $\mathrm{SiC}_{\mathrm{p}}$ up to $8 \%$ in the Al6061 matrix did not show significant difference in MRR. However, a marginal decrease of MRR is observed with increase in $\mathrm{SiC}_{\mathrm{p}}$ content.

- The machined surface showed the formation of craters and recast layers. Particularly on the recast layers, the cracks and blow holes are seen which affects the surface finish.

- $\quad$ The statistical model (average $R^{2}-73.65 \%$ ) is developed to predict the MRR which can effectively be used to estimate the MRR in wire-EDM of Al6061 with $\mathrm{SiC}_{\mathrm{p}}$ up to $8 \mathrm{wt}$. \% within the operating range ( $3 \mathrm{~A} \leq I \leq 6 \mathrm{~A} ; 20 \mu \mathrm{s} \leq t_{\text {on }} \leq 50 \mu \mathrm{s} ; 10 \mu \mathrm{s} \leq t_{\text {off }} \leq 25 \mu \mathrm{s}$; $\left.375 \mathrm{rpm} \leq w_{s} \leq 1400 \mathrm{rpm} ; 80 \mathrm{~V} \leq I_{v} \leq 90 \mathrm{~V}\right)$.

- The minimum and average prediction error of MRR from the proposed regression model is $4.45 \%$ and $20.46 \%$, respectively. An attempt can be made to reduce these errors by using advanced methods such as firefly, genetic algorithms and other natureinspired optimization methods and a comparative study of the effectiveness of optimization and predication accuracy can be made. 
Author Contributions: Conceptualization, D.D.; methodology, D.D., A.B. and S.K.; investigation, M.P.; validation, A.M.B., A.B., M.P. and S.K.; writing—original draft preparation, D.D., A.M.B., A.B. and S.K.; writing-review and editing, D.D., D.Y.P., K.G. and K.N.; funding acquisition, D.Y.P., K.G. and K.N. All authors have read and agreed to the published version of the manuscript.

Funding: This research received no external funding.

Institutional Review Board Statement: Not applicable.

Informed Consent Statement: Not applicable.

Data Availability Statement: The data presented in this study are available on request.

Acknowledgments: Authors are grateful to Manipal Institute of Technology, Manipal Academy of Higher Education, India, for providing the laboratory and material support to carry out this research work.

Conflicts of Interest: The authors declare no conflict of interest.

\section{Nomenclature}

$\begin{array}{ll}\text { ANOVA } & \text { Analysis of variance } \\ \mathrm{DF} & \text { Degree of freedom } \\ \mathrm{E}_{\mathrm{S}} & \text { Energy supplied } \\ \mathrm{F}-\text { Test } & \text { Fishers test } \\ \mathrm{I} & \text { Current } \\ \mathrm{I}_{\mathrm{V}} & \text { Input voltage } \\ \mathrm{MRR} & \text { Material removal rate } \\ \mathrm{MWCNTs} & \text { Multiwalled carbon nanotubes } \\ \mathrm{MS} & \text { Mean square } \\ \mathrm{q}_{\mathrm{R}} & \text { Maximum heat intensity } \\ \mathrm{R} & \text { Radial distance from the spark axis } \\ \mathrm{r}_{\mathrm{sp}} & \text { Plasma channel radius } \\ \mathrm{SEM} & \text { Scanning electron microscopy. } \\ \mathrm{SS} & \text { Sum of square } \\ \mathrm{SiC}_{\mathrm{p}} & \text { Silicon carbide particles } \\ \mathrm{T}_{\mathrm{on}} & \text { Pulse-on time } \\ \mathrm{T}_{\mathrm{off}} & \text { Pulse-off time } \\ \Gamma & \text { Volume of material melted } \\ \mathrm{Wire}_{\mathrm{i}} & \text { Wire-electrical discharge machining } \\ \mathrm{W}_{\mathrm{s}} & \text { Wire speed } \\ \mathrm{w}_{\mathrm{i}} & \text { Weight before the machining } \\ \mathrm{w}_{\mathrm{f}} & \text { Weight after the machining } \\ \mathrm{W}_{\mathrm{m}} & \text { Energy utilized by the material }\end{array}$

\section{References}

1. Global End Use of Aluminum Products in 2020. Available online: https://www.statista.com/statistics/280983/share-ofaluminum-consumption-by-sector/ (accessed on 22 October 2021).

2. Davis, J.R. Aluminum and Aluminum Alloys, Alloying: Understanding the Basics; ASM International: Materials Park, OH, USA, 2001; pp. 351-416. [CrossRef]

3. Suthar, J.; Patel, K.M. Processing issues, machining, and applications of aluminum metal matrix composites. Mater. Manuf. Process. 2017, 33, 499-527. [CrossRef]

4. Yigezu, B.S.; Mahapatra, M.M.; Jha, P.K. Influence of reinforcement type on microstructure, hardness, and tensile properties of an aluminum alloy metal matrix composite. J. Miner. Mater. Charact. Eng. 2013, 1, 124-130.

5. Zulfia, A.; Robby, F.; Kirman, K.; Sukarto, A. Characterization of Al-0.12Zr-0.15Ce Reinforced by Al2O3np as Composites Conductor. Int. J. Technol. 2016, 7, 383. [CrossRef]

6. Shankar, G.; Sharma, S.S.; Kini, A.; Praksh, S.; Gurumurthy, G. Influence of Artificial Aging on the Stir Cast Al6061-SiC Metal Matrix Composites under Different Aging Conditions. Int. J. Technol. 2016, 7, 1000. [CrossRef]

7. Dhaneswara, D.; Verdiyanto, R.N.; Syahrial, A.Z. The Mechanical Properties of Al2O3-Reinforced Aluminum A356 with Grain Refiner Al-5Ti-1B Fabricated using the Stir Casting Method. Int. J. Technol. 2017, 8, 1489. [CrossRef] 
8. Gu, J.; Lv, Z.; Wu, Y.; Zhao, R.; Tian, L.; Zhang, Q. Enhanced thermal conductivity of SiCp/PS composites by electro spinning hot press technique. Compos Part A-Appl. Sci. Eng. 2015, 79, 8-13. [CrossRef]

9. Gu, J.; Zhang, Q.; Dang, J.; Yin, C.; Chen, S. Preparation and properties of polystyrene/SiCw/SiCp thermal conductivity composites. J. Appl. Polym. Sci. 2011, 124, 132-137. [CrossRef]

10. Knowles, A.J.; Jianga, X.; Galano, M.; Audebert, F. Microstructure and mechanical properties of 6061 Al alloy based composites with SiC nanoparticles. J. Alloys Compd. 2014, 615, S401-S405. [CrossRef]

11. Fenghong, C.; Chang, C.; Zhenyu, W.; Muthuramalingam, T.; Anbuchezhiyan, G. Effects of Silicon Carbide and Tungsten Carbide in Aluminium Metal Matrix Composites. Silicon 2019, 11, 2625-2632. [CrossRef]

12. Nair, S.V.; Tien, J.K.; Bates, R.C. SiC-reinforced aluminium metal matrix composites. Int. Met. Rev. 2013, 30, $275-290$.

13. Matsunaga, T.; Kim, J.K.; Hardcastle, S.; Rohatgi, P.K. Casting characteristics of Aluminium alloy, Fly ash composites. Trans. Am. F 1996, 104, 1097-1102.

14. Songmene, V.; Khettabi, R.; Zaghbani, I.; Kouam, J.; Djebar, A. Machining and Machinability of Aluminum Alloys, Aluminium Alloys, Theory and Applications; Kvackaj, T., Ed.; InTech Publisher: London, UK, 2011; ISBN 978-953-307-244-9.

15. Sarikaya, M.; Gupta, M.K.; Tomaz, I.; Danish, M.; Mia, M.; Rubaiee, S.; Jamil, M.; Pimenov, D.Y.; Khanna, N. Cooling techniques to improve the machinability and sustainability of light-weight alloys: A state-of-the-art review. J. Manuf. Process. 2020, 62, 179-201. [CrossRef]

16. Slătineanu, L.; Dodun, O.; Coteaţă, M.; Nagît, G.; Băncescu, I.B.; Hriţuc, A. Wire Electrical Discharge Machining-A Review. Machines 2020, 8, 69. [CrossRef]

17. Rahman, A.; Ahmed, A.; Mia, M. Trends in electrical discharge machining of Ti- and Ni-based superalloys: Macro-microcompound arc/spark/melt process. In Micro and Nano Technologies, Micro Electro-Fabrication; Saleh, T., Ali, M.S.T., Takahata, K., Eds.; Elsevier: Amsterdam, The Netherlands, 2021; pp. 63-87.

18. Boban, J.; Ahmed, A.; Rahman, M.A. Wire electrical discharge polishing of additive manufactured metallic components. Procedia CIRP 2020, 87, 321-326. [CrossRef]

19. Pramanik, A.; Littlefair, G. Wire EDM Mechanism of MMCs with the Variation of Reinforced Particle Size. Mater. Manuf. Process. 2015, 31, 1700-1708. [CrossRef]

20. Chaudhari, R.; Khanna, S.; Vora, J.; Patel, V.K.; Paneliya, S.; Pimenov, D.Y.; Giasin, K.; Wojciechowski, S. Experimental investigations and optimization of MWCNTs-mixed WEDM process parameters of nitinol shape memory alloy. J. Mater. Res. Technol. 2021, 15, 2152-2169. [CrossRef]

21. Sivaprakasam, P.; Hariharana, G.S. Optimization of Micro-WEDM Process of Aluminum Matrix Composite (A413-B4C): A Response Surface Approach. J. Mater. Manuf. Process. 2013, 28, 1340-1347. [CrossRef]

22. Hocheng HLei WTHsu, H.S. Preliminary study of material removal in electrical-discharge machining of SiC/Al. J. Mater. Process. Technol. 1997, 63, 813-818. [CrossRef]

23. Singh, B.; Kumar, J.; Kumar, S. Influences of Process Parameters on MRR Improvement in Simple and Powder Mixed EDM of AA6061/10\%SiC Composite. Mater. Manuf. Process. 2015, 30, 303-312. [CrossRef]

24. Singh, N.; Raghukandan, K.; Rathina sabapathi, M.; Pai, B.C. Electric discharge machining of Al-10\%SiCP as-cast metal matrix composites. J. Mater. Process. Technol. 2004, 156, 1653-1657. [CrossRef]

25. Habib, S.S. Study of the parameters in electrical discharge machining through response surface, methodology approach. Appl. Math. Model. 2009, 33, 4397-4407. [CrossRef]

26. Agrawal, S.S.; Yadava, V. Modeling and prediction of material removal rate and surface roughness in surface-electrical discharge diamond grinding process of metal matrix composites. Mater. Manuf. Process. 2013, 28, 381-389. [CrossRef]

27. Singh, S.; Bhardwaj, A. Review to EDM by Using Water and Powder-Mixed Dielectric Fluid. J. Miner. Mater. Charact. Eng. 2011, 10, 199-230. [CrossRef]

28. Sidhu, S.; Batish, A.; Kumar, S. Study of Surface Properties in Particulate-Reinforced Metal Matrix Composites (MMCs) Using Powder-Mixed Electrical Discharge Machining (EDM). Mater. Manuf. Process. 2014, 29, 46-52. [CrossRef]

29. Dey, S.; Debnath, K.M. Pandey Optimization of electrical discharge machining process parameters for Al6061/cenosphere composite using grey-based hybrid approach. Trans. Nonferrous Met. Soc. China 2017, 27, 998-1010. [CrossRef]

30. Suresh Kumar, S.; Uthayakumar MThirumalai Kumaran, S.; Parameswaran, P. Electrical Discharge Machining of Al(6351)-SiCB4C Hybrid Composite. Mater. Manuf. Process. 2014, 29, 1395-1400. [CrossRef]

31. Issa, H.K.; Taherizadeh, A.; Maleki, A.; Ghaei, A. Development of an aluminum/amorphous nano-SiO2 composite using powder metallurgy and hot extrusion processes. Ceram. Int. 2017, 43, 14582-14592. [CrossRef]

32. Ravikumar, M.; Reddappa, H.; Suresh, R. Aluminium Composites Fabrication Technique and Effect of Improvement in Their Mechanical Properties-A Review. Mater. Today Proc. 2018, 5, 23796-23805. [CrossRef]

33. El-Galy, I.M.; Ahmed, M.H.; Bassiouny, B.I. Characterization of functionally graded Al-SiCp metal matrix composites manufactured by centrifugal casting. Alex. Eng. J. 2017, 56, 371-381. [CrossRef]

34. Sen, B.; Hussain, S.A.I.; Das Gupta, A.; Gupta, M.K.; Pimenov, D.Y.; Mikołajczyk, T. Application of Type-2 Fuzzy AHP-ARAS for Selecting Optimal WEDM Parameters. Metals 2020, 11, 42. [CrossRef]

35. Abbas, A.T.; Pimenov, D.Y.; Erdakov, I.N.; Taha, M.A.; El Rayes, M.M.; Soliman, M.S. Artificial Intelligence Monitoring of Hardening Methods and Cutting Conditions and Their Effects on Surface Roughness, Performance, and Finish Turning Costs of Solid-State Recycled Aluminum Alloy 6061 Chips. Metals 2018, 8, 394. [CrossRef] 
36. Lenin, N.; Sivakumar, M.; Selvakumar, G.; Rajamani, D.; Sivalingam, V.; Gupta, M.; Mikolajczyk, T.; Pimenov, D. Optimization of Process Control Parameters for WEDM of Al-LM25/Fly Ash/B4C Hybrid Composites Using Evolutionary Algorithms: A Comparative Study. Metals 2021, 11, 1105. [CrossRef]

37. Aggarwal, V.; Pruncu, C.I.; Singh, J.; Sharma, S.; Pimenov, D.Y. Empirical Investigations during WEDM of Ni-27Cu-3.15Al-2Fe1.5Mn Based Superalloy for High Temperature Corrosion Resistance Applications. Materials 2020, 13, 3470. [CrossRef]

38. Panneerselvam, R. Design and Analysis of Experiments, 1st ed.; PHI Publications: Delhi, India, 2012; ISBN -13:978-8120344990.

39. Bulent, E.; Erman, A.; Abdulkadir, E. A semi-empirical approach for residual stresses in electric discharge machining (EDM). Int. J. Mach. Tool Manufacture 2006, 46, 858-865.

40. Ozgedik, A.; Cogun, C. An experimental investigation of tool wear in electric discharge machining. Int. J. Adv. Manuf. Technol. 2005, 27, 488-500. [CrossRef]

41. Doreswamy, D.; Javeri, J. Effect of Process Parameters in EDM of D2 Steel and Estimation of coefficient for Predicting Surface Roughness. Int. J. Mach. Mach. Mater. 2018, 20, 101-117.

42. Deepak, D.; Shrinivas, P.; Hemant, G.; Iasy, R. Optimisation of Current and Pulse Duration in Electric Discharge Drilling of D2 Steel Using Graphite Electrode. Int. J. Automot. Mech. Eng. 2018, 15, 5914-5926. [CrossRef]

43. Pradana, Y.R.A.; Ferara, A.; Aminnudin, A.; Wahono, W.; Jang, J.S.-C. The Effect of Discharge Current and Pulse-On Time on Biocompatible Zr-based BMG Sinking-EDM. Open Eng. 2020, 10, 401-407. [CrossRef]

44. Moudood, M.A.; Sabur, A.; Ali, M.Y.; Jaafar, I.H. Effect of Peak Current on Material Removal Rate for Electrical Discharge Machining of Non-Conductive Al2O3 Ceramic. Adv. Mater. Res. 2013, 845, 730-734. [CrossRef]

45. Mohan, B.; Rajadurai, A.; Satyanarayana, K.G. Effect of SiC and rotation of electrode on electric discharge machining of Al-SiC composite. J. Mater. Process Technol. 2002, 124, 297-304. [CrossRef]

46. Parthiban, M.; Krishnaraj, V.; Kanchana, J.; Babu, M.K. Optimization of material removal ate in wire electric discharge grinding for micro machining of tungsten electrode. IJEMS 2018, 25, 307-314. 